\title{
INTELLIGENT PIPELINE MONITORING SYSTEM BASED on INTERNET of THINGS
}

\author{
Tomiwa Pudens Ayeni *, Bosede Aina Ayogu * \\ ${ }^{\#}$ RapidLink Technologies, Ado Ekiti, Nigeria \\ Department of Computer Science, Federal University, Oye Ekiti, Nigeria \\ Email Address \\ 1ayeni.tomiwa.pudens@gmail.com \\ DOI: $10.31364 /$ SCIRJ/v8.i8.2020.P0820793 \\ http://dx.doi.org/10.31364/SCIRJ/v8.i8.2020.P0820793
}

\begin{abstract}
The constant pipeline vandalism in Nigeria by oil saboteurs has continued to cause the nation billions of dollars every year. This act is affecting the economy of the most populous black nation and if an urgent solution is not devised, it is capable of bringing the nation to its knees. Although the Nigerian government had in the past devised different strategies to stop the act, unfortunately, most of the strategies rolled out seem to be reactive and obsolete. Internet of Things (IoT) is the technology that can help the nation monitor its pipeline facilities efficiently. To this end, we consider how IoT could be used to monitor pipelines flops in advance. This paper reviews the strategies used by oil saboteurs to steal crude oil from the nation's oil and gas pipeline facilities, highlights the strategies currently used by the Nigerian government to monitor the nation pipeline facilities, the challenges associated with the strategies and how IoT could be used to detect, control and monitors oil pipelines in an efficient manner.
\end{abstract}

Keywords- IoT, oil Pipeline, pipeline vandalism, oil saboteurs, crude oil, crude oil theft, sensors, data analysis

\section{INTRODUCTION}

The continuous decline of crude oil prices in the world market has continued to be of great concern to oil-exporting countries, as a large number of them depend largely on it as their main source of revenue. Nigeria as a case in point, four decades past, about 90 percent of the nation's total export proceeds comes from crude oil (Atlantic Council, 2017). The Federal Government of Nigeria projected about N3.73 trillion(\$9.2billion) as oil revenues out of total revenue of N8.1 trillion (\$20.9billion) to fund her 2020 national budget (Business Day, 2017). In 2019, Crude oil sold for $\$ 64$ on average per barrel against the market price of $\$ 115$ per barrel in June 2014 (Voigt et al., 2015). This price decline meant budget deficits, low foreign exchange earnings, and huge economic loss for oilexporting countries. This reality is what oil operating companies and oil-exporting countries have to deal with. Many oil and gas companies are adjusting to this reality by continuously cutting down their operational cost and constantly looking for ways to improve and elongate the value of their existing assets. To caution the effect of declined crude oil price on their nation's revenue, oil-exporting countries are tremendously increasing their production rate to export as many barrels of oil as they possibly can daily. This increase in production rate means that oil-exporting countries will have to transport more oil from production fields to the refinery and to export terminals which will make their reliance on pipeline increases. Although there are other means used globally to transport oil and gas from oil fields to refineries and the consumer markets such as tankers and rail transportation. Transporting oil by pipelines has proven to be the most viable in terms of accessibility to remote locations, distance coverage, speed, cost, and efficiency (Anifowose et al., 2008), yet most difficult assets to secure. This is because pipelines are usually very long and can span through thousands of kilometers in length and could sometimes pass through difficult terrains such as Creeks, Swamps, and area with an irregular level of access. Due to the worth of their contents, these pipelines are constantly been attacked by oil saboteurs with the intent to steal oil. Although, oil and gas operating companies have deployed different strategies in the past to secure pipeline assets, unfortunately, these strategies have largely seemed to be unsuccessful. Between 2014 and 2017, about ten thousand one and fifty-eight $(10,158)$ pipelines were vandalized In Nigeria (NADA, 2018). This meant a huge economic loss for oil and gas companies and the Nigerian government. According to the data obtained from the Nigeria Extractive Industries Transparency Initiatives, the country loses billions of dollars every year to oil theft and pipeline vandalism. Between 2009 and 2018, about $\$ 41.94$ billion in revenue was lost to oil theft and pipeline vandalism. In the first half of 2019 alone, about $\$ 1.35$ billion of revenue was also lost (Premium Times, 2019). This huge WWW.scirj.org

(C) 2020, Scientific Research Journal http://dx.doi.org/10.31364/SCIRJ/v8.i8.2020.P0820793

This publication is licensed under Creative Commons Attribution CC BY. 
revenue lost and declined in crude oil price is capable of bringing the nation's economy to its knees. Not only is pipeline vandalism causing negative impact on the nation's economy but also causing human causalities. Scores of lives and properties worth billions of naira have been lost in the past due to pipeline vandalism (NEITI, 2018; Sun et al., 2016; Vanguard, 2019). Although reports suggest that oil revenue loss is not associated only with pipeline vandalism but also with ruptured pipelines especially ageing ones, some of these pipelines have been in operation for decades and have also been subjected to different internal and external corrosion. In order to minimize revenue loss, reduce human causalities, and reduce environmental pollution caused by pipeline leaks, it is important for the oil and gas industry to devise a robust approach that would enable them to monitor, control and detect pipelines flaws in advance. This present paper is organized into sections: section 2 highlights the current pipeline monitoring strategies in Nigeria and the challenges associated with it, the review of related works is highlighted in section 3, section 4 suggest how challenges associated with the current monitoring system could be solved with Internet of Things and finally session 5 shows the conclusion.

\section{ANALYSIS OF CRUDE OIL THEFT, CURRENT MONITORING APPROACH AND ITS ASSOCIATED CHALLENGES}

For a very long time, oil theft and pipeline vandalism has continually gone unabated in the Niger Delta (south-south region), and the nation's effort to curb them have largely seem to be unsuccessful. One of the reasons is that, there is civil unrest in that region of the country. The Niger Delta militants and other grieved unemployed youth see pipeline vandalism as a means of surviving and an avenue for expressing their grievances against the perceptibly hostile and indifferent Nigerian state and the oil multinationals (Okoli, 2019).

\subsection{Strategies Used by Oil Thieves to Steal Crude Oil from Pipeline}

Oil saboteurs drill a small hole into the pipeline and attach an illegal pipeline through the hole to a high-pressure primary pipeline to illegally divert oil into barges and later send them via tankers in the Atlantic to buyers in West Africa, Europe and even as far as Asia (Al Jazeera, 2014). This process may go on for a long time undetected by authorities because a very small amount of oil is withdrawn slowly from a high-pressured pipeline. This leaves the pressure of the primary pipelines looking normal. Little wonder while the Group Managing Director of NNPC, Mele Kyari recently stated on the national television that $70 \%$ of the oil pumped from Aba to Enugu through the pipeline was lost to oil thieves without a single spill.

The other strategy used by oil saboteurs is cold tapping where a portion of a pipeline is blown up causing the authorities to shut down oil transportation through the blown pipelines. During this shutdown, a secondary pipeline unknown to the authorities is then attached to the primary pipelines through which oil is then diverted onto their barges ready to be refined through illegal refineries and sometimes to international markets. These activities can go a long time without authorities detecting since pipeline pressures may remain intact.

\subsection{Current Pipeline Monitoring Approach in Nigeria}

The first strategy currently deployed to monitor the nation's pipelines is the use of in-house security personnel. These personnel are usually non-arm carriers and are usually employed by the operating oil companies to engage other external security personnel such as local vigilantes. The vigilantes live in neighborhood housing the pipelines and usually ensures that the pipelines are protected against local intruders. Theses vigilantes get intelligent information about individuals or groups who may want to steal oil by vandalizing the pipelines. In the case of any security concern, the vigilantes communicate their concerns to the company's in-house security personnel. The Nigerian government also deploys the Joint task force (JTF) to monitor areas that have records of notorious oil saboteurs. The JTF involves collaboration of Military, Navy, Civil Defense Corps, and Mobile policemen together with the vigilantes and in-house personnel to ensure proper monitoring of pipelines, The JTF are usually gun carriers' personnel who use patrol vehicle to move around communities where pipelines are situated. The Navy also deploys the use of speed boats in areas that are inaccessible with patrol vehicles such as creeks and swamps.

The second strategy deployed by the Nigerian government to curb pipeline vandalism and oil theft in the Niger Delta area of the nation is by granting Amnesty to militants, Niger Delta is an oil-producing region of the country where there is serious militants' unrest. The amnesty program was introduced in 2009 to curb violence in the region by engaging the militants. The program focused

Www.scirj.org

(C) 2020, Scientific Research Journal

http://dx.doi.org/10.31364/SCIRJ/v8.i8.2020.P0820793

This publication is licensed under Creative Commons Attribution CC BY. 
on empowerment, human and economic development that will help the ex-militants refrain from militancy and become useful and productive citizens in their various communities with the resultant aim to help restore and sustain peace in the region (Okoli, 2019).

The last strategy deployed to monitor the nation's pipeline is the use of an internal sensor to detect changes in pressure (Achilike and MacDonald.,2017). The pressure sensor which is usually installed inside the pipelines is monitored through a remote monitoring system, If the system reports changes in pressure, then the leak is considered to have happened, the authority closes the pipeline closest valve remotely and security personnel together with engineers are deployed to intervened.

\subsection{Challenges Associated with This Current Monitoring Approach in Nigeria}

The major challenge faced with the current pipeline monitoring approaches is corruption. According to the Group Managing Director of NNPC, Mele Kyari, there is a compromise on the part of the security personnel who are supposed to monitor and provide protection for the pipelines, the community leaders housing these pipelines and the oil and gas company staff who are supposed to carry routine monitoring on the pipelines. Most of the past bunkering activities have been concentrated around Swamps, Creeks and area that are not easily accessible (Achilike and MacDonald.,2017). which makes it difficult for security personnel to intercept bunkers activities, even when the activities are detected, the bunkers would have been long gone.

The last challenge associated with the current approach is that it is a "monitor and respond" approach rather than been predictive and proactive. Due to the nature of the contents of the pipelines, it is important to detect flops in advanced so that risk associated with pipeline leaks can be minimized.

\section{STATE OF THE ART LITERATURE}

An intelligent crude oil anti-theft system based on IoT to detect crude oil leakages in the pipeline and monitor abnormal noise along with vibration in real-time was developed by Sun et al. (2016). The system is a three-tier architecture made of sensors level, transmission level, and application level. A behavioral analysis of crude oil at different stages such as oil exploration, processing, storage, and the transportation unit was examined. To develop a stable theft detection system, SCADA, IoT, and sensor unit along with a decision-making mechanism were used. The sensor unit consisted of Radio frequency identification (RFID), Cameras, temperature sensor, pressure sensor, flow sensor, GPS, Beidou, and RTU.

Achilike and MacDonald. (2017) suggested that pipeline buried technologies could be used in the place of surface pipeline deployment. The researcher discussed extensively different technologies that can be deployed to bury pipelines inland, swamps, and in deep water. Among the technologies suggested are J-lay and S-lay technologies for deep-water pipe burying, self-propelled track sled technologies for swamps pipeline burying, and trenchless technologies for land burying. It was recommended that burying pipelines between 12 to 18 feet would be sufficient to prevent vandal's access to pipelines because they are hidden beneath surfaces that are invisible to the human eyes. The shortcoming of this approach is that pipeline usually spans across a distance that is thousands in kilometers. Burying pipelines this long will be more expensive to install and maintain especially when leaks occur not as a result of vandal's activities but due to natural disasters such as an earthquake.

A multi-sensor approach which uses motion detection, vibration, and sound sensor was implemented by Aliyu et al. (2017) to monitor pipelines. A Passive Infrared (PIR) motion detection sensor was used to detect intruders before getting to the pipeline. The advantage of the PIR motion detection sensor over other motion detection sensors is its ability to differentiate between human and animal movements. The PIR sensor and vibration sensors were combined to affirm if the human is an intruder(s). A message carrying the location of the vandals is then sent to the authority-in-charge via a connected GSM module by the microcontroller for appropriate action. Their system does not consider the event where pipeline leaks can occur because of the aging pipeline and also that using a GSM module to send messages might defeat the intention in the scenario where the mobile network is not available to send SMS to notify the authority about the activities of the vandals. This study examines how IoT and multi-sensor network can be deployed to solve the current pipeline monitoring challenges.

Supervisory control and data acquisition (SCADA) is another pipeline monitoring system. It was suggested by Geiger et al. (2017) that video monitoring could be integrated into the pipeline in order to complement the existing alarm management www.scirj.org

(C) 2020, Scientific Research Journal

http://dx.doi.org/10.31364/SCIRJ/v8.i8.2020.P0820793

This publication is licensed under Creative Commons Attribution CC BY. 
visualization system and provides an additional information to SCADA operator. The shortcoming of using SCADA systems to detect leaks is that they are sparely deployed and has limited functionality. The objective of this study is to discuss an (IoT) intelligent pipeline monitoring system which is combined with Supervisory control and data acquisition (SCADA) to detect, monitor and control pipelines in real time. To achieve this objective, this study proposes a four-tier IoT based architecture which includes perception layer, network layer, processing layer and application layer.

\section{IOT MULTI-SENSORS NETWORK APPROACH FOR MONITORING OIL PIPELINE}

The current pipeline monitoring approaches in Nigeria is reactive rather than been predictive and proactive. With this current approach, it is impossible to detect leaks and vandals' activities in advanced before damage is caused on the nation's pipeline. Internet of Things (IoT) is the advanced technology that will enable industries to move from reactive approach to predictive and proactive approach. IoT is a network of physical devices empowered by sensors, actuators, identifiers, software, and internet connectivity (Ammar and Samer.,2017). In order to detect, control and monitor pipelines in real time, this study proposes a four-tier IoT based architecture consisting of perception layer, network, processing and application layer. The proposed architecture is shown in Fig.2

Application layer

\begin{tabular}{|l|l|l|l|l|l|}
\hline Reporting System & Diagnoses System \\
\hline
\end{tabular}

Processing layer

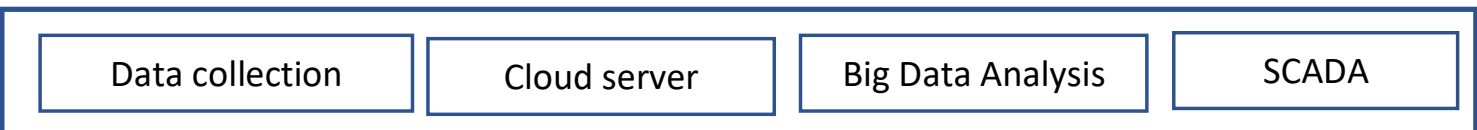

Network layer

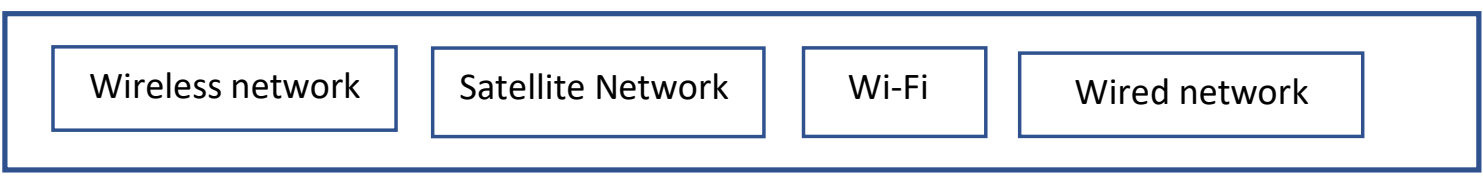

Perception Layer

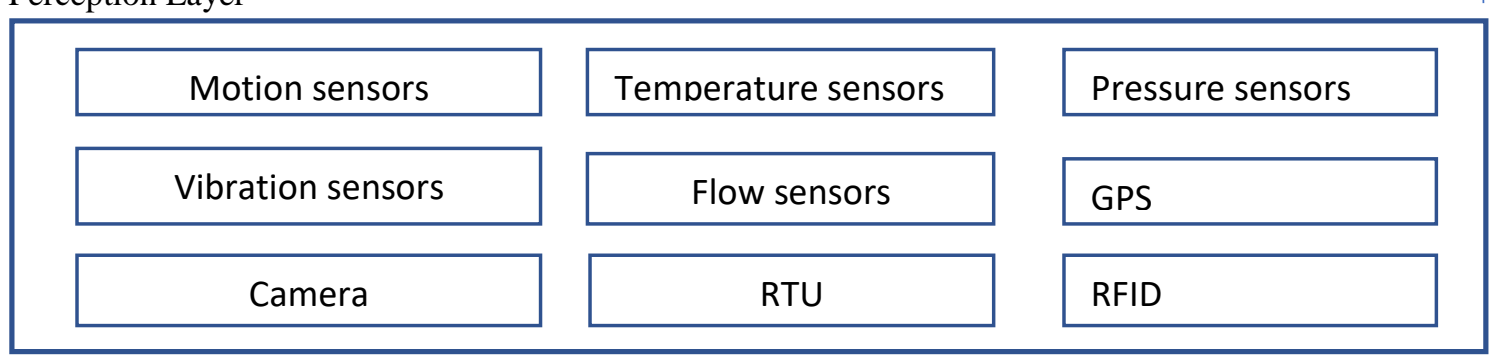

Fig.1 Four-tier IoT based architecture of intelligent pipeline monitoring system

The perception level is where interaction with the pipeline environment happens and it consists of motion sensor, pressure sensors, vibration sensors, temperature sensors, flow sensors, cameras, radio frequency identification (RFID), GPS and actuators. The motion sensor will be used to monitor any object that goes close to the target pipeline, pressure sensor is used to monitor any

www.scirj.org

(C) 2020, Scientific Research Journal

http://dx.doi.org/10.31364/SCIRJ/v8.i8.2020.P0820793

This publication is licensed under Creative Commons Attribution CC BY. 
deviation from the standard pressure by sending notification to the centralized unit for appropriate action when this deviation is observed, while vibration sensor monitors any attempt to drill hole into the pipeline or dig ground around the pipeline and a notification about this act is sent to centralized units for necessary action. Since pipeline is subjected to both internal and external temperatures which causes corrosion and eventually causes leakage, temperature sensor will be used to monitor pipeline temperature for abnormality and a notification is also sent to the centralized unit for action when any abnormality is observed. Flow sen sor will be used to monitor the rate of flow of oil and send notification against any noticeable abnormality, when any abnormality is detected GPS will assist the authority in charge to know the exact location of the incident, RFID will be used to uniquely identify the pipeline and information about the pipeline can be obtained in real time by interrogating the RFID tag through a reader. These sensors will interact with themselves through a unique addressing scheme.

Network layer is the intermediary layer between the perception layer and processing layer. In order to transmit sensor data such text, images and videos collected in the perception layer to the processing layer in real time, Wi-Fi, wireless and satellite network will be used. Wi-Fi and other communication will be used to communicate over short-range and 4G/5G will be used for faster long-range communication.

Processing layer is where data collected at the perception is been stored, analyzed and processed intelligently for the purpose of deriving useful insight from it. Technologies used at this layer includes database, cloud computing and big data processing. Big data analysis tools such as A/B testing, data fusion, data mining, and machine learning will be used. Intelligent decision-making will be through Artificial intelligence (AI)

Application layer is the layer that the user directly interacts with, this is where the insight drawn from the processing unit is presented visually to users. Notifications, warnings and reports is also presented to users in this layer. In the case of any impending dangers or critical warning about the pipeline facilities, diagnosis and control of the system will be done at this layer.

\section{CONCLUSIONS}

With the continuous decline in the price of crude oil in the international market, there is an urgent need for oil-producing nations to safeguard their oil pipeline facilities from oil saboteurs in order to save their earnings from oil and gas production, this will in no small measure contributes to the funding of their national budget and boost their foreign exchange earnings. To this end, this study proposes a four-tier IoT based architecture consisting of perception layer, network, processing, and application layer. The system suggests the use of sensors such as motion, pressure, vibration, temperature, camera, GPS, and flow rate sensors to perceive the pipeline environment.

\section{REFERENCES}

[1] NEITI, 2018. \$42B Lost to Crude Oil and Products Theft in Ten Years. https://neiti.gov.ng/index.php/mediacenter/news/487-neiti-42b-lost-to-crude-oil-and-products-theft-in-ten-years ,[Accessed April 1, 2020].

[2] Premium Times, 2019. Nigeria loses $\$ 1.35$ billion to oil theft in six months. https://www.premiumtimesng.com/news/headlines/353301-nigeria-loses-1-35-billion-to-oil-theft-in-six-months.html, [Accessed May 2 2020].

[3] Sun, J., Zhong, Z., Sun, X.,2016. The intelligent crude oil anti-theft system based on ICT under different scenarios. In:20 ${ }^{\text {th }}$ International Conference on Knowledge Based and Intelligent Information and Engineering System KES2016, 5-7, York, United Kingdom.pp.1581-1588.

[4] Anifowose, B., Lawler D., Horst D.V., Chapman L., 2008. Transportation in Nigeria's oil and gas industry: An environmental challenge. In: Proceedings of the Postgraduate Researcher's Conference, Meeting Environmental Challenges in the Coastal Region of Nigeria.pp.1-11

[5] Vanguard 2019. Breaking: Many feared killed as pipeline explodes in Ijegun-Ikotun, Lagos.vanguardngr.com/2019/07/breaking-oil-pipeline-explodes-in-ijegun-ikotun-lagos/ [Accessed May2, 2020].

[6] Economic Confidential, 2020.Pipelines Attack: Nigeria loses over $\$ 42 \mathrm{bn}$ revenue. https://economicconfidential.com/2020/01/pipelines-attack-42bn-revenue/ [Accessed May 2, 2020].

www.scirj.org

(C) 2020, Scientific Research Journal

http://dx.doi.org/10.31364/SCIRJ/v8.i8.2020.P0820793

This publication is licensed under Creative Commons Attribution CC BY. 
[7] Achilike C., MacDonald., 2017. Securing Nigeria's crude oil and gas pipelines - change in current approach \& focus on the future. ISSN 2201-2796.

[8] National Bureau of statistics. https://www.nigerianstat.gov.ng/.[accessed May 11 2020]

[9] YouTube ,2020. GMD NNPC on Good Morning Nigeria: Persistent Pipeline ExplosionLag.https://www.youtube.com/watch?time_continue=140\&v=45iKwUZwweg\&feature=emb_title.[Accessed May 11,2020].

[10] Tobor, J.A., Odubo, A.,2017. Amnesty Program as a Peacebuilding Initiative in Niger Delta, Nigeria, ISSN: 2151-6200. doi: 10.4172/2151-6200.1000272.

[11] Adeojo A.O., Onumanyi A., Ayanya J.M., Oyewobi S.O., 2013.Oil and gas process monitoring through wireless sensor network survey. Journal of Applied Science.ISSN 1943-2429. pp.39-43.

[12] Naira Metrics,2016. Nigeria lost $\$ 750$ million to crude oil theft in 2019. https://nairametrics.com/2020/02/19/nigeria-lost-750-million-to-crude-oil-theft-in-2019-nnpc/ . [Accessed May 04, 2020].

[13] Voigt, A., Walls, B., McKemey, M., 2015.Drowning in oil: Indicators of instability in low price environment

[14] Business Day,2017. How Nigeria's falling oil production may affect 2020 budget revenue. Retrieved from https://businessday.ng/short-take/article/how-nigerias-falling-oil-production-may-affect-2020-budget-revenue/ [Accessed 15 May 2020].

[15] Okoli, A.C., 2019. Oil pipeline vandalism in the Niger Delta. https://www.accord.org.za/conflict-trends/oil-pipelinevandalism-in-the-niger-delta/

[Accessed May 15, 2020].

[16] Al Jazeera. (2014). Tracking oil theft in Nigeria. https://www.aljazeera.com/indepth/inpictures/2014/09/pictures-tracking-oiltheft-nig-201498195636567970.html [Accessed May 15, 2020].

[17] Atlantic Council,2017. Downstream Oil Theft Global Modalities, Trends, and Remedies. https://www.atlanticcouncil.org/wp-content/uploads/2017/01/Downstream_Oil_Theft_web_0327.pdf .[Accessed May 16, 2020].

[18] Salihu O. Aliyu, Innocent O. Agbo, Saidu Muslim, Elizabeth N. Onwuka,Multi-Sensor Approach for Monitoring Pipelines, International Journal of Engineering and Manufacturing (IJEM), Vol.7, No.6, pp.59-72, 2017.DOI: 10.5815/ijem.2017.06.06

[19] Ammar, R., Samer, S., 2017. Internet of Things from Hype to Reality the Road to Digitization. Springer Nature Switzerland AG, 393pp.

[20] Geiger, G., Hazel,T .,Vogt D.,2010.Integrated SCADA-based approach for pipeline security and operation, ISSN: 2161-812, https://doi.org/10.1109/PCIC.2010.5666821

[21] Aftab, H., Gilani, K., Lee, J., Nkenyereye, L., Jeong, S., Song J.,2019. Analysis of identifiers on IoT platforms, ISSN: 23528648,https://doi.org/10.1016/j.dcan.2019.05.003

www.scirj.org

(C) 2020, Scientific Research Journal

http://dx.doi.org/10.31364/SCIRJ/v8.i8.2020.P0820793

This publication is licensed under Creative Commons Attribution CC BY. 